\title{
Escape from Tolentino During an Earthquake Saving as Many Lives and Cultural Objects as You Can
}

\author{
Paola Pazzaglia and David Scaradozzi
}

\begin{abstract}
In the last five years, the Italian Ministry of Education has placed its focus on digital skills, recognizing them as fundamental and indispensable for the growth of future citizens in the information age. It has thus backed projects aimed at developing computational thinking and digital creativity at school. One of the highest-funded of such projects is "Più vicini al nostro territorio-Valorizziamo $i$ monumenti di Tolentino ... giocando con Scratch e App Inventor" (Closer to our territory-appreciating the value of Tolentino's monuments ... while playing on Scratch and App Inventor). In this paper we describe this project, its vertical path, and the results of the first activities, which have already taken place in a primary school. These results show the progression of the skills and competences defined in the National Operational Programme document "For school 2014-2020" (Axis I Education, Objective 10.2, Improving students' key competences), and those set out in the National Plan for Digital Education.
\end{abstract}

Keywords Digital competences $\cdot$ Coding $\cdot$ Educational robotics $\cdot$ STEM . Primary school $\cdot$ Nintendo labo

\footnotetext{
P. Pazzaglia $(\varangle)$

Istituto Comprensivo “G. Lucatelli” Viale Benadduci, 23, 62029 Tolentino, Monte Cassino, Italy

D. Scaradozzi

Department of Information Engineering (DII), Università Politecnica Delle Marche, Via Brecce Bianche, 60131 Ancona, Italy

LSIS - Umr CNRS 6168 Laboratoire des Sciences de L'Information et des Systèmes, Equipe I\&M (ESIL) case 925 - 163 avenue de Luminy, 13288 Marseille cedex 9, France

D. Scaradozzi

e-mail: d.scaradozzi@univpm.it
} 


\section{Introduction}

Many researchers have been investigating the use of coding and robots to support education. Studies have shown that robots can help students develop problem-solving abilities and learn computer programming, mathematics, and science. The educational approach, based mainly on developing logic and creativity in new generations from the first stages of education, is very promising. Introducing coding and robotic systems is fundamental to the achievement of these aims, if begun at an early stage of education. At primary school, coding and robot programming are fun, making them excellent tools for introducing children to ICT and helping them develop their logical and linguistic abilities. In the last five years, the Italian Ministry of Education has placed its focus on digital skills, recognizing them as fundamental and indispensable for the growth of future citizens in the information age. It has thus backed projects aimed at developing computational thinking and digital creativity at school. While considering how to engage girls and boys in an activity with the potential to motivate them to consider a future career in STEM-related fields, the authors drew on personal experience (see from [1-9]) and on findings in the literature of great results obtained using educational robotics (ER) for the same aim. First, Benitti [10] reviewed ER experiences from around the world. Her results show that there is great potential in ER methodologies and activities in K12 classrooms, but the full power of these research outcomes still needs to be thoroughly exploited. Mubin et al. [11] highlight the great effort that research still needs to make to produce appropriate curricula that include robotics. Veselovská and Mayerová [12], on the other hand, present a qualitatively assessed ER activity in the context of an ER curriculum at lower secondary school. Sanders [13] considers robotics to be the real integrated approach to STEM education: rather than these four subjects addressing it separately as a mere series of notions, they could come together to re-elaborate these notions as part of active learning. Moreover, the benefits of ER education can also come in the form of cybersecurity [14], a STEM-related field that can empower future citizens of the digital world and protect today's boys and girls from the potential dangers of connected life. The authors have conducted coding and robotics teaching experiences in Italian schools since 2000-2001, when the first project was proposed. It was called "Building a robot" and a description of it can be found in [8]. This paper presents the project entitled "Più vicini al nostro territorio-Valorizziamo i monumenti di Tolentino ... giocando con Scratch e App Inventor" (Closer to our territory-appreciating the value of Tolentino's monuments ... while playing on Scratch and App Inventor). The main aim of this project is to encourage primary school students to experience the creative process, in spite of the earthquake, and to foster their literacy in their local heritage. The activities included the creation of a board game simulating Tolentino during an earthquake. Players have to escape from the town, saving as many lives and cultural objects as possible. In this paper we describe the project, the vertical path within it, and the results of the first activities, which have already taken place in a primary school. These results show the progression of the skills and competences 
defined in the National Operational Programme document "For school 2014-2020" (Axis I Education, Objective 10.2, Improving students' key competences), and those set out in the National Plan for Digital Education.

\section{Material and Methods}

The following subsections provide an account of the project activities.

\subsection{Underlying Pedagogical Approach}

The pedagogical theory used for the design and execution of the activities in this project is constructionism. Its premise is that knowledge building is the natural consequence of creating and experimenting. Students are encouraged to observe their own actions directly and to analyze the consequent effects. They are asked to share ideas in a highly motivating context. Here, technology and innovative learning environments give students room to learn in their own distinct style. Drawing on Howard Gardner's theory of multiple intelligences, students are encouraged to acknowledge their own skills and abilities. This can help them to think about their future, in terms of both their studies and their careers. Problem-based learning (PBL), a learner-centered approach, was employed. After a short explanation of the fundamental aspects of the project, students were given challenges to search collaboratively for effective solutions. Thus, they were also involved in project-based learning and peer tutoring. All the activities were designed on the TMI model (Think, Make, Improve), as suggested by Martinez and Stager [15]. First, students try to figure out what a solution to the problem might look like (Think); second, they try to implement the solution by building and programming the board game (Make); third, they look at their artefacts closely and try to debug or improve them, by using different points of view or by sharing their ideas with others (Improve). The methodology adopted is learning by doing, in other words, learning from experience. According to Dewey, learning should not be passive, but rather relevant and practical. This hands-on approach allows students to learn through practical tasks, after which their experience must be accompanied by thinking over and reflecting. To be effective, this methodology needs students to reflect, revise and integrate the experience. For this reason, each lesson included a session of sharing, when each group shared its work with the others and reflected on it. Moreover, peer tutoring was applied during coding activities (with Scratch), during which students worked collaboratively with others, improved relationships and increased motivation. 


\subsection{Tools and Materials}

In the first module of the project, primary school students (aged 9-10) began to learn to code with Scratch 3, the free, easy-to-learn and visual programming language, and used Lego WeDo 2.0 for educational robotics activities. They went to school one afternoon a week to find out about the main principles of coding. They used their knowledge and applied their creativity to invent a board game that is both physical and virtual. The purpose of the game is to find out about the most important monuments in their town, Tolentino. Lessons were organized as hands-on learning laboratories in which students worked in teams of two or three sharing ideas and helping each other. The second part of the project started in October 2019 and is still in progress. Students from the lower secondary school are completing the board game using Scratch, APP Inventor and QR code.

\subsection{Learning Objectives and Competences}

The learning objectives and competences developed in the first part of the project were to: promote and develop computational thinking, coding and the use of digital technologies; encourage students' interest in STEM; improve soft skills, especially critical thinking, analyzing ability, problem-solving, planning skills, team working; reinforce logical reasoning; rediscover and enhance Tolentino's artistic and historical monuments.

\subsection{Contents of the Activities}

The activities included the creation of a board game simulating Tolentino during an earthquake. Players have to escape from the town, saving as many lives and cultural objects as possible. The module introduced the basic concepts of coding using Scratch. The teaching progression was:

- coding: introduction to Scratch: simple animations and experiments. Basic functions of Scratch and first sprite movements;

- coding: sequence of instructions and animations: drawing geometric shapes with Scratch. Starting with polygons (triangle, square ...) students continued creating their own pictures;

- coding: cyclical repetition of instructions;

- coding and logic: synchronizing events: after the stories were created in analogical form (using paper, pen and storyboard), the children reproduced them with Scratch; 
- robotics: basic principles of robotics; man-machine-robots: similarities and differences; building a robot using a Lego WeDo 2.0 kit and programming it with Scratch 3; programming challenges;

- robotics exercise: each group of children is asked to watch by a video captured during an earthquake and design and build a mechanism that reproduces the movement of the ground (undulation). Initially, some houses with weak foundations collapse, until the designed system is able to withstand powerful impacts generated by the WeDo engine;

- cultural heritage literacy: find information about Tolentino's most important monuments and their distinctive features;

- storytelling: be a tourist guide in Tolentino using Scratch;

- basic principles of gamification: how do you design a game? Brainstorming during which students discussed their points of view about a board game;

- creation of the board and markers from paper and recycled materials;

- final exhibition: students showed the board game to parents and teachers.

\subsection{Expected Results}

- Improving the learning process and school performance and motivating the students involved in the project.

- Developing new knowledge and competences in digital technologies, coding and computational thinking.

- Increased interest in STEM.

- Improved teamwork.

- Improved problem-solving and analytical skills.

- Learning the very basics of coding.

- Rediscovery and appreciation of Tolentino's most important monuments.

- Understanding how to behave during an earthquake.

\section{Preliminary Results}

The preliminary results are based on the activities described in Sect. 2, carried out over a given period of time. The proposed criteria turned out to be suitable for teaching new concepts to children, for attributing coherent purpose to building an application for tablets and a robot, and for teaching them the history of their town and the importance of the right behavior during an earthquake. Selected groups of professional operators were also invited to observe and to take part in the intermediate tests and experiments. Università Politecnica delle Marche will assess the activity by means of questionnaires $[2,5]$. The first experimental project was carried out at Istituto Comprensivo "Lucatelli" in Tolentino, Italy. Primary School teacher Paola Pazzaglia, University professor David Scaradozzi, and Talent s.r.l. developer 
Federico Camilletti developed the experimental project after their observation of primary school students. The project focused on increasing and pursuing logic and creativity as important educational skills in modern school. They were able to start the project.

The preliminary results are based on a comparison of the following items:

- higher marks (before and after the project) in some subjects, such as Italian, English, mathematics and science, showed the students had improved in those areas;

- the students' attitude, as they were always curious and grew more and more interested, especially when they understood the importance of working as a group to gain new skills while, at the same time, being able to deal with new problems;

- through systematic observation, it was possible to see an overall improvement in the EU competences, too (only those closely related to the project) (Figs. 1, 2 and 3).

Fig. 1 Children looking for information about

Tolentino's monuments

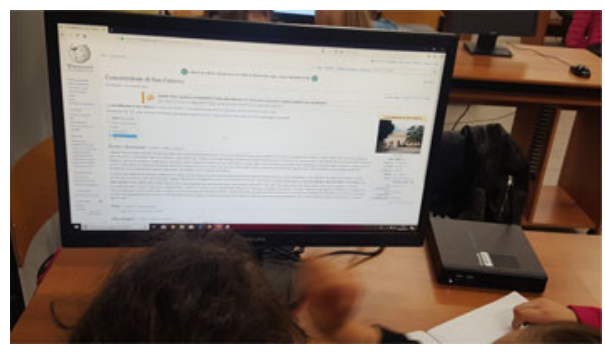

Fig. 2 One of the mechanisms children built using Lego WeDo 2.0 that reproduces the undulations of the earth

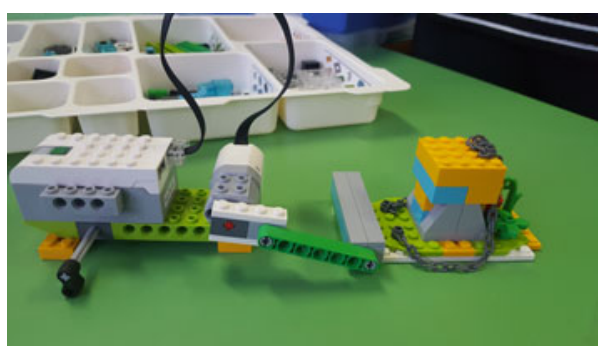

Fig. 3 The game's board

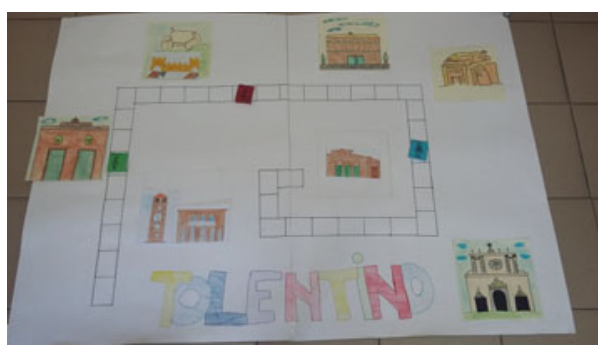




\section{References}

1. Scaradozzi, D., Cesaretti, L., Screpanti, L., Costa, D., Zingaretti, S., \& Valzano, M.: Innovative tools for teaching marine robotics, IOT and control strategies since the primary school. In: Smart Learning with Educational Robotics, pp. 199-227. Springer, Cham (2019)

2. Scaradozzi, D., Screpanti, L., Cesaretti, L.: Towards a definition of educational robotics: a classification of tools, experiences and assessments. In: Smart Learning with Educational Robotics, pp. 63-92. Springer, Cham (2019)

3. Screpanti, L., Cesaretti, L., Marchetti, L., Baione, A., Natalucci, I.N., Scaradozzi, D.: An educational robotics activity to promote gender equality in STEM education. In: International Conference on Information, Communication Technologies in Education (ICICTE 2018) Proceedings. Chania, Greece (2018)

4. Scaradozzi, D., Screpanti, L., Cesaretti, L., Mazzieri, E., Storti, M., Brandoni, M., Longhi, A.: Rethink Loreto: we build our smart city!" A stem education experience for introducing smart city concept with the educational robotics. In: 9th Annual International Conference of Education, Research and Innovation (ICERI 2016). Seville, Spain (2016)

5. Scaradozzi, D., Screpanti, L., Cesaretti, L., Storti, M., Mazzieri, E.: Implementation and assessment methodologies of teachers' training courses for STEM activities. Technol. Knowl. Learn. 24(2), 247-268 (2019)

6. Cesaretti, L., Storti, M., Mazzieri, E., Screpanti, L., Paesani, A., Principi, P., Scaradozzi, D.: An innovative approach to school-work turnover programme with educational robotics. Mondo Digitale 16(72), 2017-2025 (2017)

7. Scaradozzi, D., Pachla, P., Screpanti, L., Costa, D., Berzano, M., Valzano, M.: Innovative robotic tools for teaching STREM at the early stage of education. In: Proceedings of the 10th Annual International Technology, Education and Development Conference, INTED (2016)

8. Scaradozzi, D., Sorbi, L., Pedale, A., Valzano, M., Vergine, C.: Teaching robotics at the primary school: an innovative approach. Procedia Soc. Behav. Sci. 174, 3838-3846 (2015)

9. Morganti, G., Perdon, A.M., Conte, G., Scaradozzi, D.: Multi-agent system theory for modelling a home automation system. In: International Work-Conference on Artificial Neural Networks, pp. 585-593. Springer, Berlin, Heidelberg (2009)

10. Benitti, F.B.V.: Exploring the educational potential of robotics in schools: a systematic review. Comput. Educ. 58(3), 978-988 (2012)

11. Mubin, O., Stevens, C.J., Shahid, S., Al Mahmud, A., Dong, J.J.: A review of the applicability of robots in education. J. Technol. Educ. Learn. 1(209-0015), 13 (2013)

12. Veselovská, M., Mayerová, K.: Programming constructs in curriculum for educational robotics at lower secondary school. In: International Conference EduRobotics 2016, pp. 242-245. Springer, Cham (2016)

13. Sanders, M.E.: Stem, stem education, stemmania (2008)

14. Kasemsap, K.: Robotics: theory and applications. In: Moore, M. (ed.), Cybersecurity Breaches and Issues Surrounding Online Threat Protection, pp. 311-345. IGI Global (2017)

15. Martinez, S.L., Stager, G.: Invent to learn: making, tinkering, and engineering in the classroom. Constructing modern knowledge press, Torrance, CA (2013) 
Open Access This chapter is licensed under the terms of the Creative Commons Attribution 4.0 International License (http://creativecommons.org/licenses/by/4.0/), which permits use, sharing, adaptation, distribution and reproduction in any medium or format, as long as you give appropriate credit to the original author(s) and the source, provide a link to the Creative Commons license and indicate if changes were made.

The images or other third party material in this chapter are included in the chapter's Creative Commons license, unless indicated otherwise in a credit line to the material. If material is not included in the chapter's Creative Commons license and your intended use is not permitted by statutory regulation or exceeds the permitted use, you will need to obtain permission directly from the copyright holder.

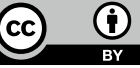

